\title{
Hot Deformation Behavior of a New Nuclear Use Reduced Activation Ferritic/Martensitic Steel
}

\author{
Chao Liu ${ }^{1} \cdot$ Ming-Chun Zhao ${ }^{1} \cdot$ Tuguldur Unenbayar $^{1} \cdot$ Ying-Chao Zhao $^{1} \cdot$ Bin Xie $^{1} \cdot$ Yan Tian $^{1} \cdot$ \\ Yi-Yin $\mathrm{Shan}^{2} \cdot \mathrm{Ke}$ Yang $^{2}$
}

Received: 20 July 2018/Revised: 14 September 2018/Published online: 23 November 2018

(C) The Chinese Society for Metals and Springer-Verlag GmbH Germany, part of Springer Nature 2018

\begin{abstract}
The hot deformation behavior and workability of a new reduced activation ferritic/martensitic steel named SIMP steel for accelerator-driven system were studied. The flow curve and its microstructure were studied at $900-1200{ }^{\circ} \mathrm{C}$ and strain rate range of 0.001-10 s $\mathrm{s}^{-1}$. The results showed that the deformation behavior of the SIMP steel during hot compression could be manifested by the Zener-Hollomon parameter in an exponent-type equation. Based on the obtained constitutive equation, the calculated flow stresses were in agreement with the experimentally measured ones, and the average activity energies $Q_{\mathrm{DRV}}$ and $Q_{\mathrm{HW}}$ for the initiation of dynamic recrystallization and the peak strain were calculated to be $476.1 \mathrm{~kJ} / \mathrm{mol}$ and $462.7 \mathrm{~kJ} / \mathrm{mol}$, respectively. Furthermore, based on the processing maps and microstructure evolution, the optimum processing condition for the SIMP steel was determined to be $1050-1200{ }^{\circ} \mathrm{C} / 0.001-0.1 \mathrm{~s}^{-1}$.
\end{abstract}

Keywords Reduced activation ferritic/martensitic steel · Hot deformation - Flow curve Constitutive equation . Processing map

\section{Introduction}

The minimization of nuclear waste is the key factor to the sustainable development of fission powers. Recently, a new type of nuclear reactor, accelerator-driven system (ADS), which is a promising concept for future high-level radioactive waste reduction and destruction of the long-lasting actinides resulted from the fission reactors by transmutation, is one of the most promising alternatives to solve this problem and has received high attention [1]. The reduced activation ferritic/martensitic (RAFM) steel, which has better thermal conductivity, lower thermal expansion coefficient and much better resistance to swelling than austenitic steels, has been considered as a promising

Available online at http://link.springer.com/journal/40195

Ming-Chun Zhao

mczhao@csu.edu.cn

1 School of Material Science and Engineering, Central South University, Changsha 410083, China

2 Key Laboratory of Nuclear Materials and Safety Assessment, Institute of Metal Research, Chinese Academy of Sciences, Shenyang 110016, China candidate structure material for both the first wall and the spallation target applications in ADS [2]. F82H, EUROFER97 and 9Cr2WVTa have been studied as the preferential materials in Japan, Europe and the USA, respectively [3].

Nowadays, a new nuclear use reduced activation martensitic steel, named SIMP steel which is developed by the advanced structural materials team from the Institute of Metal Research, Chinese Academy of Sciences, is expected as one of the candidate structural materials for ADS of next-generation nuclear reactors in China [4]. The SIMP steel is designed for harsh operating conditions caused by high temperatures, high neutron flux and contact with liquid lead-bismuth eutectic (LBE).

Recent studies [5, 6] showed that the SIMP steel presents a better corrosion resistance than the T91 steel in the oxidation and LBE environments. Similar to the Russian dual-phase heat-resistant steel EP823, the SIMP steel shows a good corrosion resistance by modifying the contents of chromium and silicon [7, 8]. In order to reduce the high activation elements in the SIMP steel, molybdenum and niobium are substituted by tungsten and tantalum, while nickel and cobalt are removed concurrently. Besides, the steel is controlled to obtain a full martensitic 
microstructure without $\delta$-ferrite which acutely deteriorates toughness of the steel.

Hot working processing plays an important role in the steel production which requires not only dimensional accuracy but also specified microstructures and mechanical properties [9-13]. Moreover, maintaining superior and stable properties after the hot working process will become a key factor in the future application of the SIMP steel. The processing map, which is developed from the flow data of thermal compression test, is very important to the optimization of processing conditions as well as the revelation of the influence of hot processing parameters on microstructure evolution [14]. However, the hot deformation behavior and the processing map of the SIMP steel that could be used to optimize the forming processing parameters and control the microstructures were unknown.

On the basis of hot deformation behavior of the SIMP steel by constant strain rate compression test, the application of the SIMP steel constitutive equations for determination of hot working constants was critically discussed in this paper. After establishing the constitutive equation for the SIMP steel, the accurate positions where different softening processes took place were determined precisely. Then, the hot workability was illustrated by the instability and processing maps, and the optimum processing conditions for the SIMP steel were confirmed.

\section{Experimental}

The chemical composition of the SIMP steel is shown in Table 1. The steel was melted in a vacuum inductionmelting furnace and then forged into a bar with a diameter of $20 \mathrm{~mm}$ at $1150{ }^{\circ} \mathrm{C}$. The specimens for compression test were cut from the center of the bar and machined into dimensions of $8 \mathrm{~mm}$ in diameter and $12 \mathrm{~mm}$ in gauge length. The initial microstructure of the specimens is full martensite, and the grain size is $40-50 \mu \mathrm{m}$.

Compression tests at different strain rates and different temperatures were carried out on a Gleeble-3500 thermalmechanical simulator to explore the deformation characteristics of the experimental steel. All the specimens were homogenized in argon gas at $1200{ }^{\circ} \mathrm{C}$ for $5 \mathrm{~min}$ and then cooled to the deformation temperatures of $900-1200{ }^{\circ} \mathrm{C}$ at a rate of $10{ }^{\circ} \mathrm{C} / \mathrm{s}$. After soaking at the deformation temperature for $1 \mathrm{~min}$, the specimens were compressed in a single hit to a true strain of $1.2(\sim 70 \%$ height reduction) at strain rate range of $0.001-10 \mathrm{~s}^{-1}$. In order to ensure uniform deformation and minimize the frictional effect, a tantalum foil with thickness $0.05 \mathrm{~mm}$ was introduced between the indenter and transverse surface of the specimen. The specimens were quenched to room temperature in water immediately upon the completion of compression. The specimens were cooled rapidly in water to preserve the as-deformed microstructure. The procedures are illustrated in Fig. 1.

The continuous stress-strain curves under all deformation conditions were obtained in order to critically analyze the operating mechanisms occurring at various stages of the flow curves and calculate the constitutive parameters. Compressed specimens were cut at approximately 1/3 of the diameter from the edge using an electrical discharge machine to avoid defects and uneven structures, which is to ensure the accuracy and stability of thermal deformation. The longitudinal section of the machined specimens was then polished and etched to examine the microstructures under different operating conditions.

\section{Results and Discussion}

\subsection{Flow Curves and Microstructures}

Figure 2 shows the true stress-strain curves of the SIMP steel at five different strain rates $\left(0.001-10 \mathrm{~s}^{-1}\right)$ and different temperatures $\left(900,1000,1050,1100\right.$ and $1200{ }^{\circ} \mathrm{C}$ ). Flow curves under all strain rates at high temperature ( $\geq 1050{ }^{\circ} \mathrm{C}$ ) showed a distinct peak except for the strain rate of $1 \mathrm{~s}^{-1}$ and $10 \mathrm{~s}^{-1}$ at $1050{ }^{\circ} \mathrm{C}$. Beyond the critical point, the stress continued to increase until the softening due to the progress of the dynamic recrystalization (DRX) balanced the continuing strain hardening in the unrecrystalized parts of the material. The balance can be manifested by the peak stress $\sigma_{\mathrm{p}}$ attained at the strain $\varepsilon_{\mathrm{p}}$ in a distinct peak. The softening process was prevalent till strains of 0.4-0.6, while after that, a monotonous increase in the true stress was observed on almost all the curves, indicating that the previously formed balanced state was broken and the hardening process took priority again beyond the strain of 0.6 .

With the decrease in temperature and the increase in strain rate, both $\varepsilon_{\mathrm{p}}$ and $\sigma_{\mathrm{p}}$ increased in a similar manner. The peak which likely occurred at a relatively higher temperature broadened and finally disappeared when the temperature decreased and the strain rate increased continuously. The absence of balance, which is shown as a
Table 1 Chemical compositions of experimental SIMP steel (wt $\%)$

\begin{tabular}{llllllllll}
\hline $\mathrm{C}$ & $\mathrm{Si}$ & $\mathrm{Cr}$ & $\mathrm{Mn}$ & $\mathrm{W}$ & $\mathrm{Ta}$ & $\mathrm{V}$ & $\mathrm{Nb}$ & $\mathrm{S}$ & $\mathrm{P}$ \\
\hline 0.22 & 1.22 & 10.24 & 0.52 & 1.45 & 0.12 & 0.18 & 0.01 & 0.0043 & 0.0040 \\
\hline
\end{tabular}




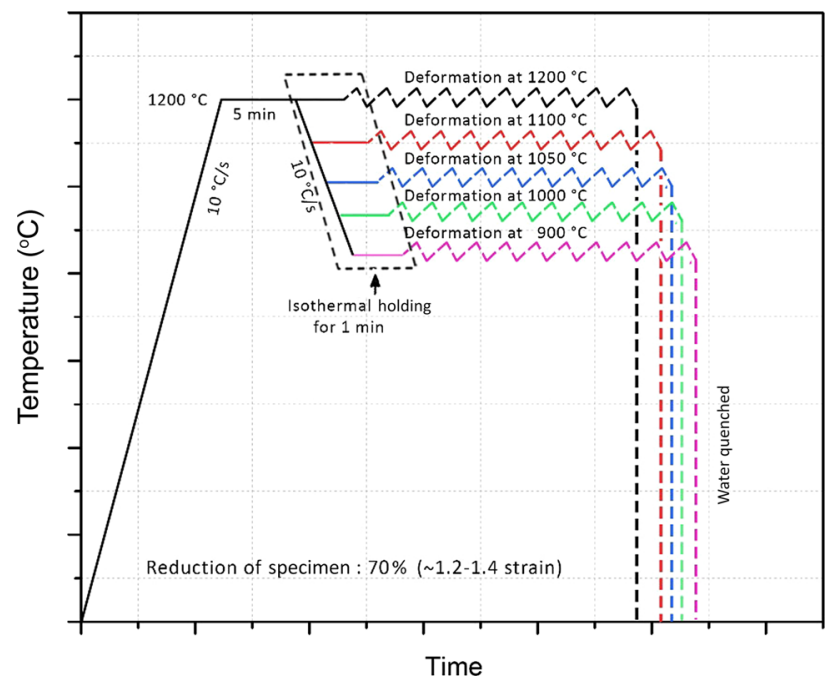

Fig. 1 Complete experimental procedures for hot deformation of SIMP steel

monotonous increase at lower temperature and high stain rate, could be attributed to stronger work hardening which proves to be the dominant process over the softening process. That is to say, the increase in the stress could be attributed to the dominant effect of work hardening mechanism over softening mechanism taking place such as DRX and dynamic recovery (DRV). The $\varepsilon_{\mathrm{p}}$ and $\sigma_{\mathrm{p}}$ were consequently delayed or disappeared completely due to the effect of solute strengthening by solute content, such as $\mathrm{Cr}$, Mo and W. Earlier study by McQueen et al. [15] suggested that solute strengthening is the possible reason of the increase in flow stress. The solute elements could diminish DRV by raising the dislocation density through pinning effect of the Cottrell atmosphere or reduction in the stacking fault energy.

Generally speaking, the flow stress $(\sigma)$ of a metal material increases with the rising strain rate $(\dot{\varepsilon})$ at a certain deformation temperature. This increasing effect of strain rate on flow stress is a reflection of the effective strain rate sensitivity $m(\partial \log \sigma / \partial \log \dot{\varepsilon})$ of the material. The flow curves of the SIMP steel, however, showed that increase in strain rate is less effective in increasing the flow stress at lower temperature. The stress augmentation ratio $\left(r_{i-}\right.$ $\left.=\left(\left(\sigma_{i}-\sigma_{1}\right) / \sigma_{1}\right)\right)$ (where $r_{\mathrm{i}}$ is the stress augmentation ratio for the flow curve, $\sigma_{i}$ is the peak stress of the flow curve, $i=1-5$ represents the strain rate of $0.001,0.01,0.1,1$ and $10 \mathrm{~s}^{-1}$, respectively) in terms of the maximum stress at different deformation temperatures is shown in Table 2. The $r$ values range between 0.97 and 4.43 at the temperature of $1200{ }^{\circ} \mathrm{C}$, much higher than the range between 0.25 and 1.13 at the temperature of $900{ }^{\circ} \mathrm{C}$. It is clear that the stress augmentation ratio $r$ diminishes with the decrease in temperature, which is the same as that of the study by (a)

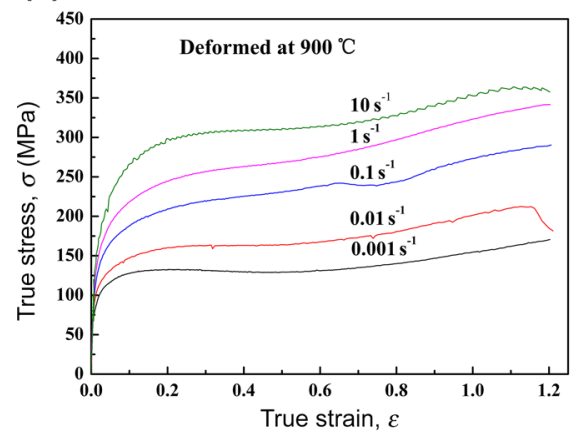

(b)

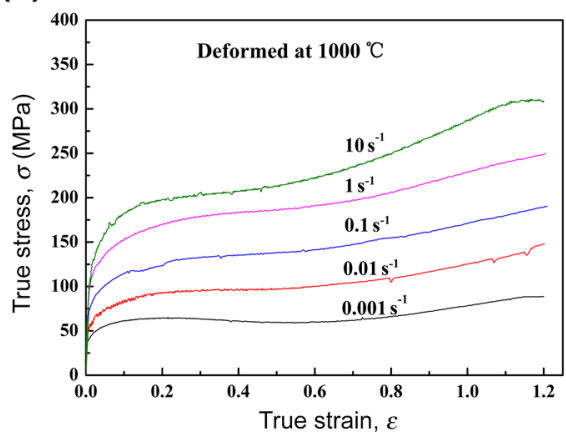

(c)

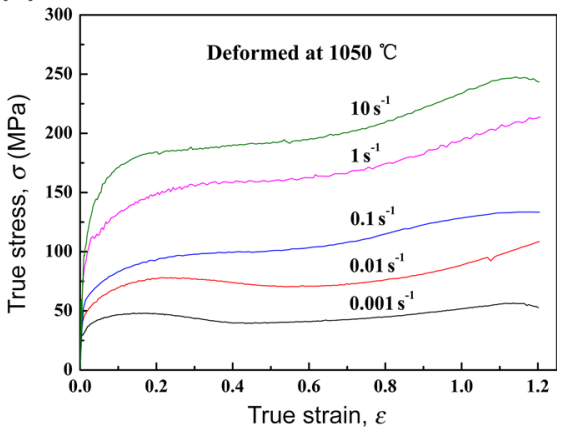

(d)

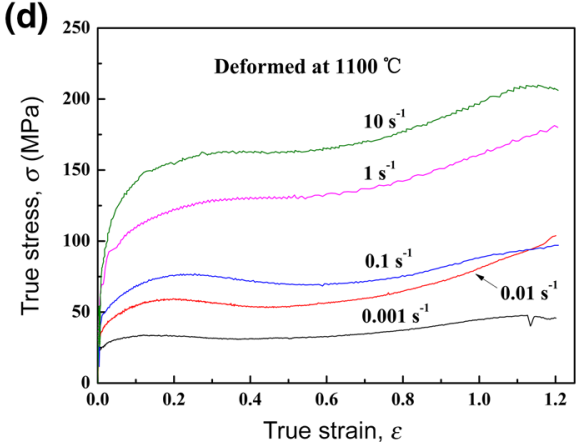

(e)

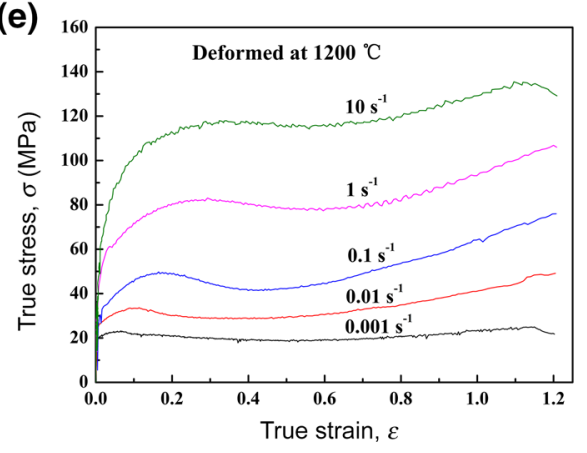

Fig. 2 True stress-strain curves of the SIMP steel deformed at $900{ }^{\circ} \mathrm{C} \mathrm{a}, 1000{ }^{\circ} \mathrm{C} \mathrm{b}, 1050{ }^{\circ} \mathrm{C} \mathrm{c}, 1100{ }^{\circ} \mathrm{C} \mathrm{d}, 1200{ }^{\circ} \mathrm{C} \mathbf{e}$ 
Table 2 Maximum stress augmentation ratio at different deformation temperatures

\begin{tabular}{lllll}
\hline Temperature $\left({ }^{\circ} \mathrm{C}\right)$ & $r_{2}$ & $r_{3}$ & $r_{4}$ & $r_{5}$ \\
\hline 900 & 0.25 & 0.70 & 1.00 & 1.13 \\
1000 & 0.67 & 1.15 & 1.81 & 2.50 \\
1050 & 0.92 & 1.36 & 2.78 & 3.38 \\
1100 & - & 1.03 & 2.80 & 3.40 \\
1200 & 0.97 & 2.04 & 3.28 & 4.43 \\
\hline
\end{tabular}

Zhang et al. [16] on nitride-strengthened steel and martensitic heat-resistant steel as well as that of 304 stainless steel by Taylor and Hodgson [17]. The reason why the effective strain rate sensitivity $m$ diminishes is that dislocations recombine harder and the stacking fault energy is lower with the decrease in temperature.

Microstructural observations (Fig. 3) under different deformation conditions showed that the average grain size increased with the decrease in the strain rate and the increase in the temperature. The specimen deformed at $900{ }^{\circ} \mathrm{C}$ and strains of $0.1 \mathrm{~s}^{-1}$ and $10 \mathrm{~s}^{-1}$ (Fig. 3a, e) show that the grains were elongated, implying the fact that only dynamic recovery occurred under these conditions. Microstructures for the specimens deformed at strain rate of $0.1 \mathrm{~s}^{-1}$ and 1000,1100 and $1200{ }^{\circ} \mathrm{C}$ (Fig. 3b-d) exhibit dynamically recrystallized grain structures. The microstructures for specimens deformed at 1100 and $1200{ }^{\circ} \mathrm{C}$ and strain rate of $10 \mathrm{~s}^{-1}$ (Fig. 3g, h) also exhibit the features of DRX. The average grain sizes of the specimen deformed at strains of $0.1 \mathrm{~s}^{-1}$, and the temperatures of 1000,1100 and $1200{ }^{\circ} \mathrm{C}$ are about 8,20 and $48 \mu \mathrm{m}$, respectively, while the average grain sizes of the specimen deformed at strains of $10 \mathrm{~s}^{-1}$ and the temperatures of 1000 , 1100 and $1200{ }^{\circ} \mathrm{C}$ are around $6.5,10$ and $21 \mu \mathrm{m}$, respectively. Microstructures at lower temperatures, i.e., at around $900-1000{ }^{\circ} \mathrm{C}$ and $\dot{\varepsilon}=0.1$ (Fig. 3a), show serrated grain boundaries forming a necklace-type structure with small grains at former grain boundaries and very small DRX grains. Since DRX involves repeated nucleation but limited growth of new grains, the mean grain size varied slightly as recrystallization proceeded. Furthermore, the similar DRX grain size occurred at strain rates of $0.1 \mathrm{~s}^{-1}$ and $10 \mathrm{~s}^{-1}$ and at $1000{ }^{\circ} \mathrm{C}$, which was attributed to the higher dislocation density accumulation in the case of high strain rate, resulting in a higher driving force for the initiation of DRX. Therefore, the repeated nucleation taking place in the DRX process reduced the growth driving force, leading to smaller dynamically recrystallized grains at lower temperature and/or higher strain rate (compared to Fig. $3 \mathrm{c}, \mathrm{d}, \mathrm{h}$ ). In contrast with the temperature increased and/or the strain rate decreased, the strain hardening was reduced, allowing faster growth of the new recrystallized grains in all directions.

\subsection{Determination of Critical Condition for DRX}

Dynamic recrystallization (DRX) has been recognized as a key factor in controlling the structure and properties of metals under industrial processing operations. Typically, in the hot-deformations, the occurrence of DRX is characterized by the appearance of a peak on the flow curve $[18,19]$. But this assumption is not always true. Taylor and Hodgson [17] revealed that DRX occurred in 304 stainless steel, while no distinctive peak was observed in the flow curve. Zhang et al. [16] and Mirzadeh and Najafizadeh [20] also discovered the same phenomenon in nitride-strengthened steel, martensitic heat-resistant steel and copper, respectively. It has been found that the curves which did not show any peak indicated incomplete DRX. The critical strain for DRX can usually be obtained from the stressstrain data, which is easier than the microstructural observation. Many theories have been proposed so far regarding the onset of DRX by flow curves analysis, but the method used by Ryan and McQueen has been widely accepted and used [21]. They suggested that the presence of a stress peak on a constant strain rate flow curve leads to an inflection in the stress dependence of the strain hardening rate, $\theta(=\partial \sigma / \partial \dot{\varepsilon})$. Then, the approximate location where the DRX starts can be confirmed.

The $\theta-\sigma$ plot corresponding to the above stress-strain curve is shown in Fig. 4. The working hardening rate would taper off as the strain went to arbitrarily large value in the absence of DRX, e.g., $900{ }^{\circ} \mathrm{C} / 10 \mathrm{~s}^{-1}$. If DRX occurred, however, a flection would emerge on the downward curves, e.g., $1200{ }^{\circ} \mathrm{C} / 0.01 \mathrm{~s}^{-1}$. The value of saturation stress $\sigma_{\mathrm{s}}$ can be obtained by the extrapolation of the lower linear $\theta-\sigma$ segment to $\theta=0$ if only DRV occurs. The critical position for DRX is identified as the point on the $\theta-\sigma$ curve where the intersection of the lower linear $\theta-\sigma$ segment and extrapolation line is. The peak stress value is determined by the work hardening rate curve dropping to the $X$ axis. Unfortunately, the flection of the work hardening rate curve at $900{ }^{\circ} \mathrm{C} / 10 \mathrm{~s}^{-1}$ is unconspicuous, which is different from the conditions at $1050{ }^{\circ} \mathrm{C} /$ $0.1 \mathrm{~s}^{-1}$ and $1200{ }^{\circ} \mathrm{C} / 0.01 \mathrm{~s}^{-1}$. The $\theta-\sigma$ plot at $900{ }^{\circ} \mathrm{C} /$ $10 \mathrm{~s}^{-1}$ reveals that the strain hardening rate decreased to a minimum and then climbed up before $\theta=0$, i.e., the balance between work hardening and dynamic softening could not be presented. This method was not clear at all used to confirm the onset of DRX at $900{ }^{\circ} \mathrm{C} / 10 \mathrm{~s}^{-1}$.

Actually, the energy consideration is the other approach to locate the onset of DRX. Poliak and Jonas [22] developed an alternative method based on the thermodynamics of irreversible processes, where the minimum of $-\partial \theta / \partial \sigma$ 

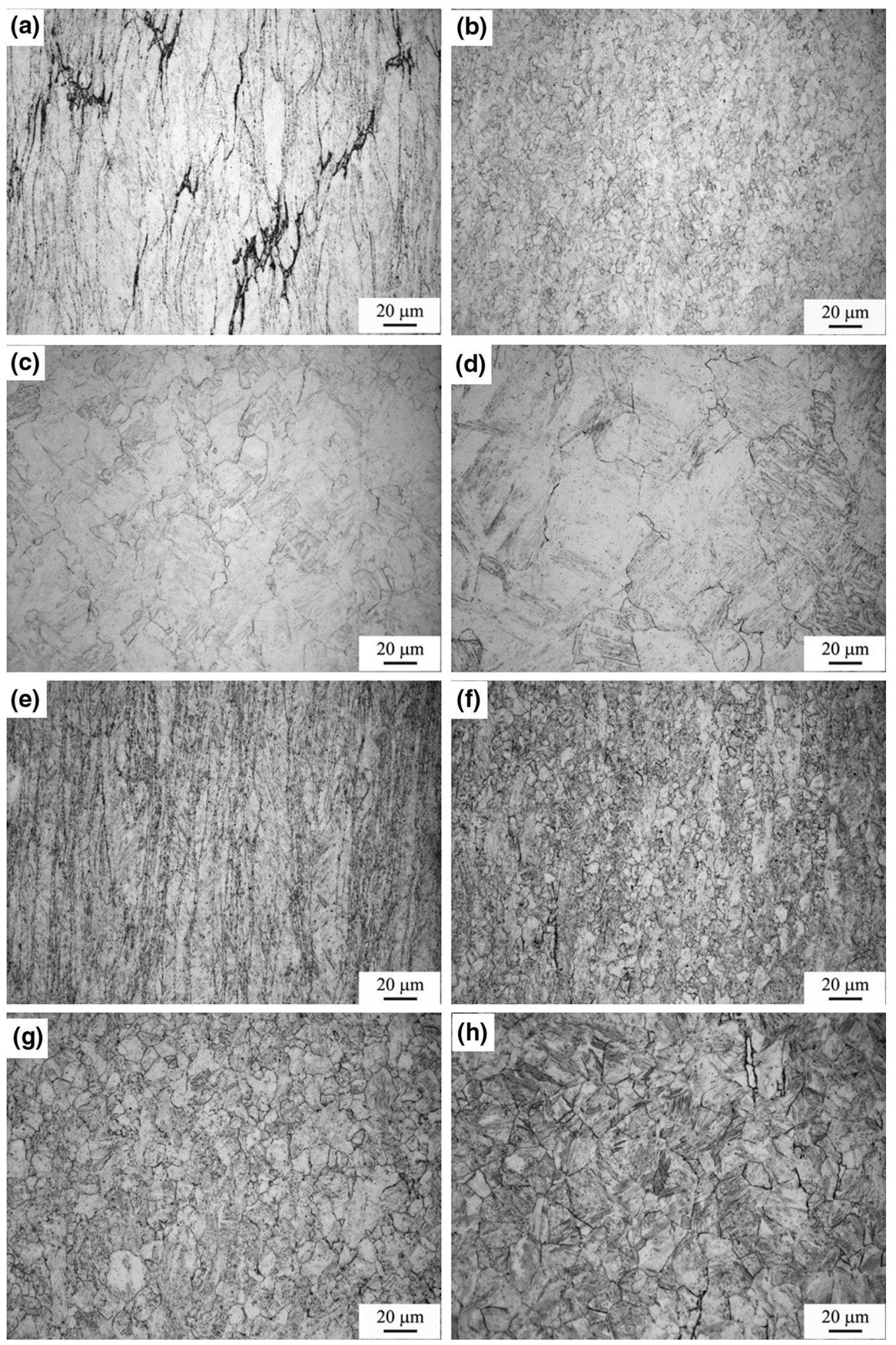

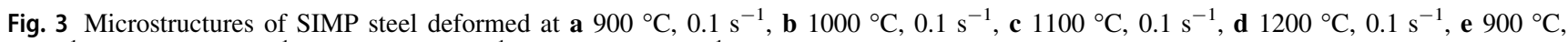
$10 \mathrm{~s}^{-1}, \mathbf{f} 1000{ }^{\circ} \mathrm{C}, 10 \mathrm{~s}^{-1}, \mathbf{g} 1100{ }^{\circ} \mathrm{C}, 10 \mathrm{~s}^{-1}, \mathbf{h} 1200{ }^{\circ} \mathrm{C}, 10 \mathrm{~s}^{-1}$ 


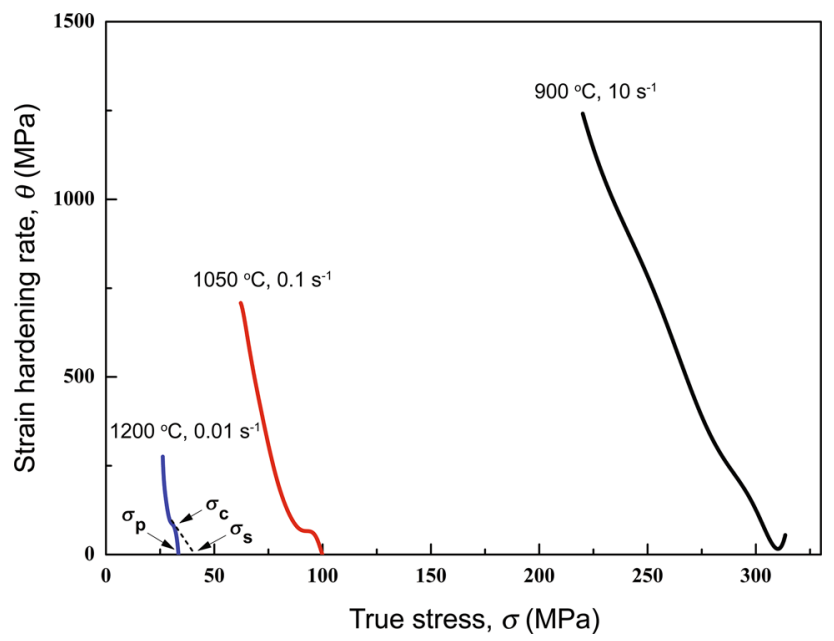

Fig. 4 Strain hardening rate plots for SIMP steel ( $\sigma_{\mathrm{c}}$ : critical stress)

can act as the characterizing position when DRX started. They suggested that the initiation of DRX requires two essential conditions including attaining critical amount of local store energy and the minimum energy dissipation rate. The $-\partial \theta / \partial \sigma-\sigma$ curves are depicted in Fig. 5 for the SIMP steel and the critical stresses are precisely obtained as $241.2,92.8$ and $30.6 \mathrm{MPa}$ at $900{ }^{\circ} \mathrm{C} / 10 \mathrm{~s}^{-1}, 1050{ }^{\circ} \mathrm{C} /$ $0.1 \mathrm{~s}^{-1}$ and $1200{ }^{\circ} \mathrm{C} / 0.01 \mathrm{~s}^{-1}$, respectively. Particularly worth mentioning is that the $-\partial \theta / \partial \sigma$ value at $900{ }^{\circ} \mathrm{C} /$ $10 \mathrm{~s}^{-1}$ has a minimum value, that is to say, the DRX occurred but is incomplete under this condition. The critical and peak stress could be applied to locate the critical and peak strain via the initial flow curve.

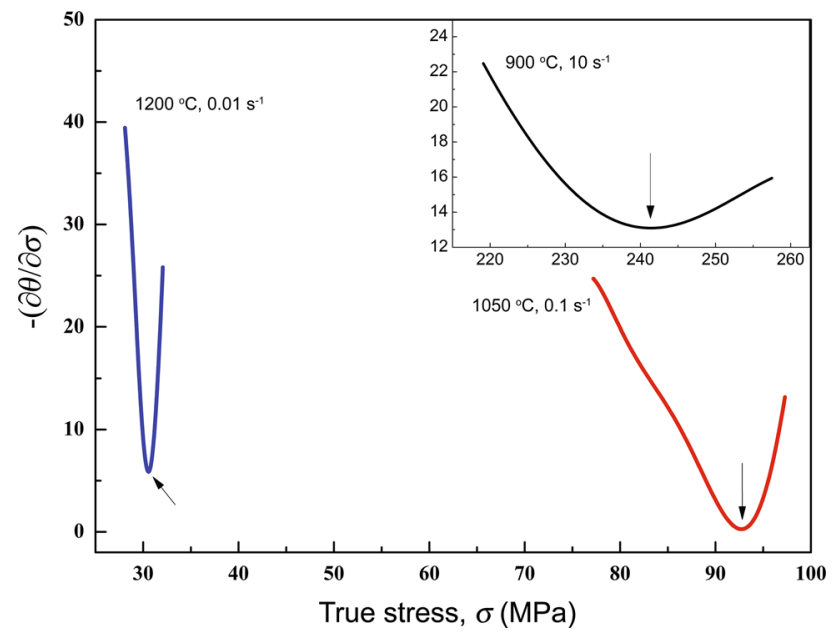

Fig. 5 Flow stress dependence of $-\partial \theta / \partial \sigma$ for SIMP steel (The inset shows the minimum point of the second numerical derivative of flow curves as a function of stress at the inflection point of work hardening curve. This unique minimum point gives a good estimate of the critical stress)

\subsection{Constitutive Equation}

Similar to studies on creep, hot working also can be considered as a thermally activated process and can be described by strain rate equations [23, 24]. The constitutive equations including an Arrhenius term are most widely used to describe the relationship among the strain rate, flow stress and temperature, especially at high temperature. The effects of temperature and strain rate on the deformation behavior can be manifested by Zener-Hollomon parameter $(Z)$ in an exponent-type equation. Generally, the relationship between $Z$ value and flow stress can be successfully represented by the hyperbolic law in Arrhenius-type equation which gives better approximations under a wide deformation condition. The activation energy and the material constant coefficient for the SIMP steel in deformation can be calculated by the following constitutive equation [25]:

$Z=\dot{\varepsilon} \exp (Q /(R T))=A[\sinh (\alpha \sigma)]^{n}$,

where $Q$ is the activation energy $Q, T$ is the deformation temperature, $A$ is material constant, the stress exponent $n, \alpha$ is a fixed constant for material and $R$ the gas constant $(8.314 \mathrm{~J} /(\mathrm{mol} \mathrm{K}))$. The stress multiplier $\alpha$ is an adjustable constant which brings $\alpha \sigma$ into the correct range that gives linear and parallel lines in the logarithmic coordinate system.

Equation (1) has approximate terms at different range of stress, which have been perfectly fitted at low stress and high stress, respectively. The terms can be expressed by:

$Z=A^{\prime} \sigma^{n^{\prime}}$,

$Z=A^{\prime \prime} \exp (\beta \sigma)$,

where $A^{\prime}, A^{\prime \prime}, n^{\prime}$ and $\beta(\approx \alpha n)$ are material constants. By taking natural logarithm of Eqs. (1)-(3), the following expressions can be derived:

$\ln A+n \ln [\sinh (\alpha \sigma)]$,

$\ln Z=\ln \dot{\varepsilon}+Q /(R T)=\ln A^{\prime}+n^{\prime} \ln \sigma$,

$Z=A^{\prime \prime}+\beta \sigma$.

In these expressions, both the strain rate and absolute temperature during deformation are corresponding to the flow stress. Meanwhile, the characterizing strain of deformation mechanism for all flow curves such as peak, steady state, critical strain for initiation of DRX should be taken into consideration. Then, the nature constants for material and equations can be recognized by the characteristic stress. In our study, there were many cases where the peaks were absent or unclear on the curve. Choosing the critical stress is actually more appropriate than peak stress which is 
the most widely accepted one in order to find the hot working constants.

By partial differentiation of these expressions at constant temperature, equations of $n=[\partial \ln \dot{\varepsilon} / \partial \ln \sinh$ $\left.\left(\alpha \sigma_{\mathrm{c}}\right)\right]_{T}, n^{\prime}=\left(\partial \ln \dot{\varepsilon} / \partial \ln \sigma_{\mathrm{c}}\right)_{T}$, and $\beta=\left(\partial \ln \dot{\varepsilon} / \partial \sigma_{\mathrm{c}}\right)_{T} \quad$ can be derived and the value of $\alpha\left(\approx \beta / n^{\prime}\right)$ can be calculated. The useful plots are displayed in Fig. 6. We used the critical value of stress $\sigma_{\mathrm{c}}$ at the temperatures of $1200{ }^{\circ} \mathrm{C}$ and $1100{ }^{\circ} \mathrm{C}$ for the calculation of $n^{\prime}$ and $1000{ }^{\circ} \mathrm{C}$ and $900{ }^{\circ} \mathrm{C}$ for the calculation of $\beta$ in order to obtain the $\alpha$ value. These temperatures were chosen because the power and the exponential functions held valid at high and low temperatures, respectively. The values of $n^{\prime}$ and $\beta$ are calculated to be 5.90724 and 0.07236 , respectively. The $\alpha$ value calculated from these results is $0.01225 \mathrm{MPa}^{-1}$. This value is close to the common value of $0.012 \mathrm{MPa}^{-1}$ for stainless steel which is lower than the value of $0.014 \mathrm{MPa}^{-1}$ for the carbon steels and HSLA steels [15]. Then, the value of $n=5.12764$ at DRX nucleation for the SIMP steel was obtained by using the $\alpha$ value and critical stress $\sigma_{\mathrm{c}}$ in the hyperbolic sine law.

Re-arranging Eq. (4) differently:

$\ln [\sinh (\alpha \sigma)]=\frac{\ln \dot{\varepsilon}-\ln A}{n}+\frac{Q}{n R T}$.

By plotting $\ln [\sinh (\alpha \sigma)]$ against $(1 /(n R T))$ at constant strain rates, the activation energy at DRX nucleation position $Q_{\mathrm{DRV}}$ can be acquired from the slope of the linear regression lines in Fig. 7. The $Q_{\mathrm{DRV}}=476.1 \mathrm{~kJ} / \mathrm{mol}$ for the SIMP steel at critical strain is an average from the slopes of five fitting straight lines, which was obtained by five tests of strain rates. Substituting the $n$ and $Q_{\mathrm{DRV}}$ values

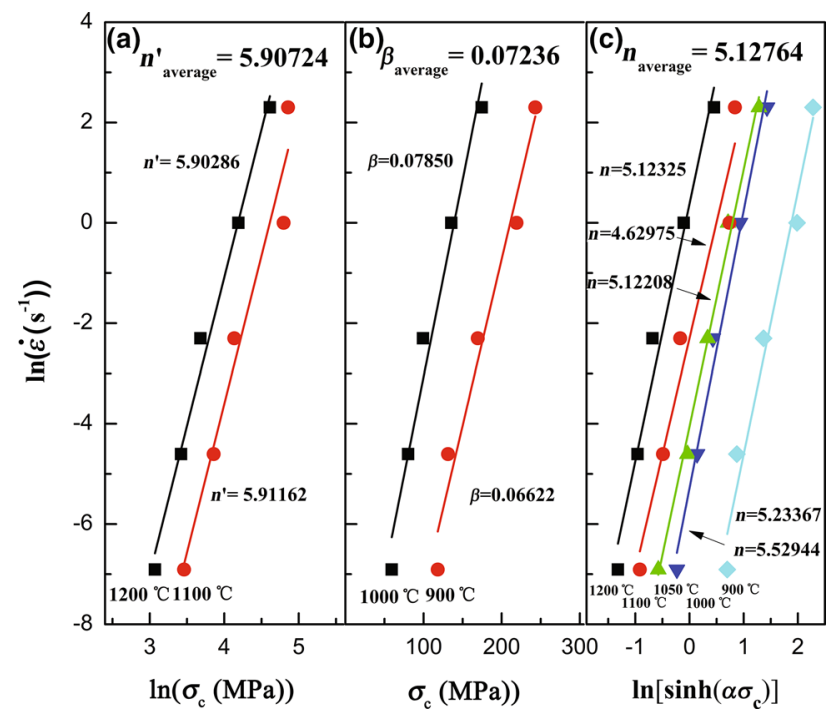

Fig. 6 Plots of $\mathbf{a} \ln \dot{\varepsilon}-\ln \sigma_{\mathrm{c}}, \mathbf{b} \ln \dot{\varepsilon}-\sigma_{\mathrm{c}}$ and $\mathbf{c} \ln \dot{\varepsilon}-\ln \left[\sinh \left(\alpha \sigma_{\mathrm{c}}\right)\right]$ for calculation of hot working constants for SIMP steel

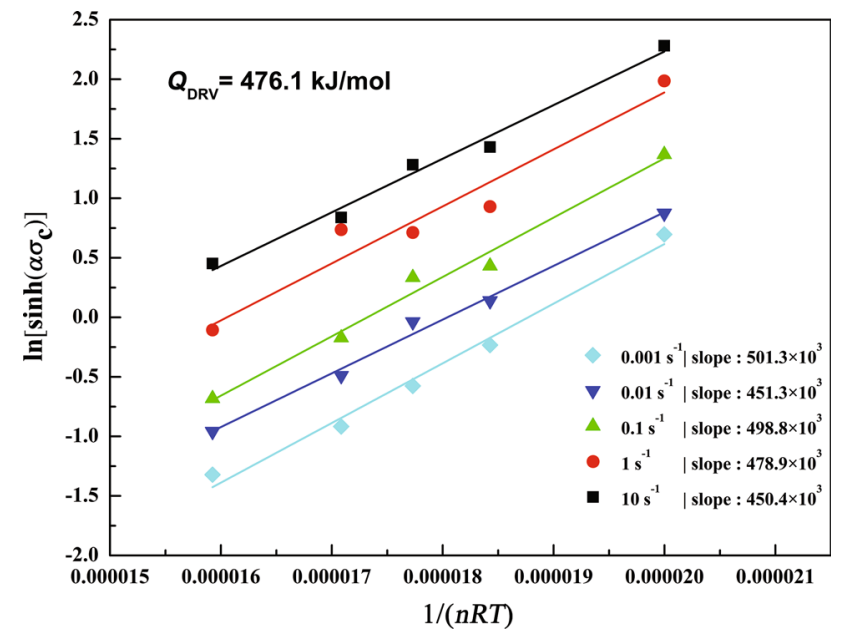

Fig. 7 Linear relationship of $\ln \left[\sinh \left(\alpha \sigma_{\mathrm{c}}\right)\right]$ versus $(1 / n R T)$

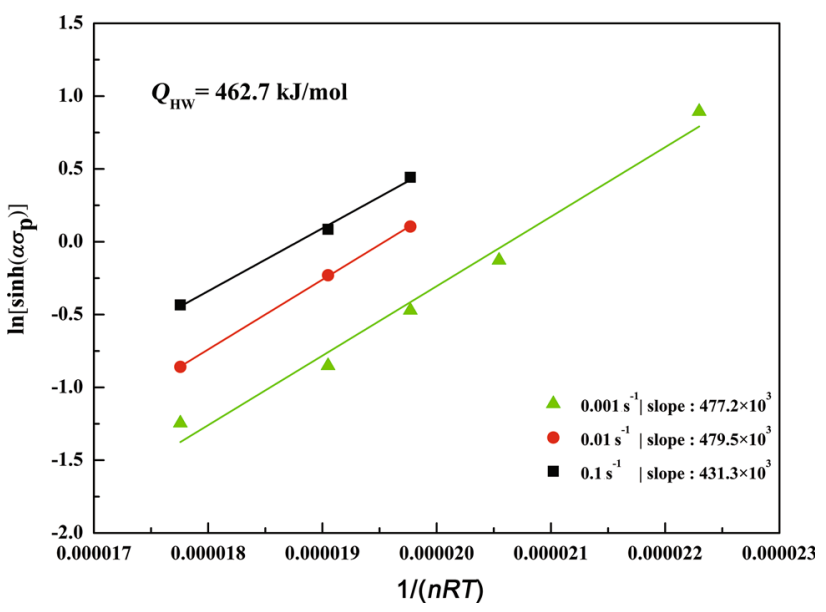

Fig. 8 Linear relationship of $\ln \left[\sinh \left(\alpha \sigma_{\mathrm{p}}\right)\right]$ versus $(1 / n R T)$

into Eq. (1), the average value of $A$ is obtained to be $1.27 \times 10^{17}$.

Using the above method, the activation energy at peak location $Q_{\mathrm{HW}}$ is obtained by the curves presenting a peak during hot working process, as shown in Fig. 8. The values of $A$, the stress exponent $n^{*}$ and $Q_{\mathrm{HW}}$ for peak stress were obtained to be $1.62 \times 10^{16}, 4.59871$ and $462.7 \mathrm{~kJ} / \mathrm{mol}$, respectively. The similar activation energy in different hot deformation mechanisms (only DRV and DRV+DRX) shows that the DRX process did not increase the value of $Q$ for the SIMP steel.

The activation energy $Q_{\mathrm{HW}}=462.7 \mathrm{~kJ} / \mathrm{mol}$ for the SIMP steel is slightly higher than the $437 \mathrm{~kJ} / \mathrm{mol}$ and $439 \mathrm{~kJ} / \mathrm{mol}$ derived in the previous studies on the hot working activation energy for P92 [26] and a $12 \%$ Cr USC rotor steel [27], respectively. However, it is much higher than the $280 \mathrm{~kJ} / \mathrm{mol}$ and $315 \mathrm{~kJ} / \mathrm{mol}$ measured for relatively pure iron and P91 [28], respectively. The significant difference might be attributed to the higher solute 
strengthening by $\mathrm{Si}, \mathrm{W}$ and $\mathrm{Ta}$. The increase in dissolved carbon content cannot increase the activation energy as it enhances $\gamma$-iron self-diffusion coefficient only.

According to the above analysis, the constitutive equation for the SIMP steel at the deformation temperature over a large range of $900-1200{ }^{\circ} \mathrm{C}$ can be expressed as:

$$
\begin{aligned}
Z & =\dot{\varepsilon} \exp (476100 /(R T)) \\
& =1.27 \times 10^{17}\left[\sinh \left(0.01225 \sigma_{\mathrm{c}}\right)\right]^{5.12764}, \\
Z & =\dot{\varepsilon} \exp (462700 /(R T)) \\
& =1.62 \times 10^{16}\left[\sinh \left(0.01225 \sigma_{\mathrm{c}}\right)\right]^{4.59871} .
\end{aligned}
$$

\subsection{Relationship of Zener-Hollomon Parameter and Characterized Point}

The Zener-Hollomon parameter always acts as a characteristic combination of the effects of temperature and strain rate in the hot deformation process. It can serve as a single value stating how $\sigma$ rises as $Z$ increases, thus permitting the comparison of the characteristics under different deformation conditions.

In the SIMP steel, the measured characterized point as a function of $Z$ is shown in Figs. 9 and 10. Figure 9 shows the variation of peak strain and DRX initialization critical strain with the increase of $Z$. The root mean square error is 0.364157967 and the coefficient of correlation is 0.3355 for the fitted curves of critical strain, while the root mean square error is 0.178048078 and the coefficient of correlation is 0.873 for the fitted curves of critical strain. The value of $\ln \varepsilon_{\mathrm{c}}$ increases with rising $\ln Z$ before the $\ln Z$ value is around 40 , since only a small strain is required to initiate the DRX at low $Z$ value with the increase in $Z$ value. However, this increase tends to level off when the value of $\ln Z$ is beyond 40 , which is explained as that the increase in $Z$ value under high $Z$ condition can lead to the

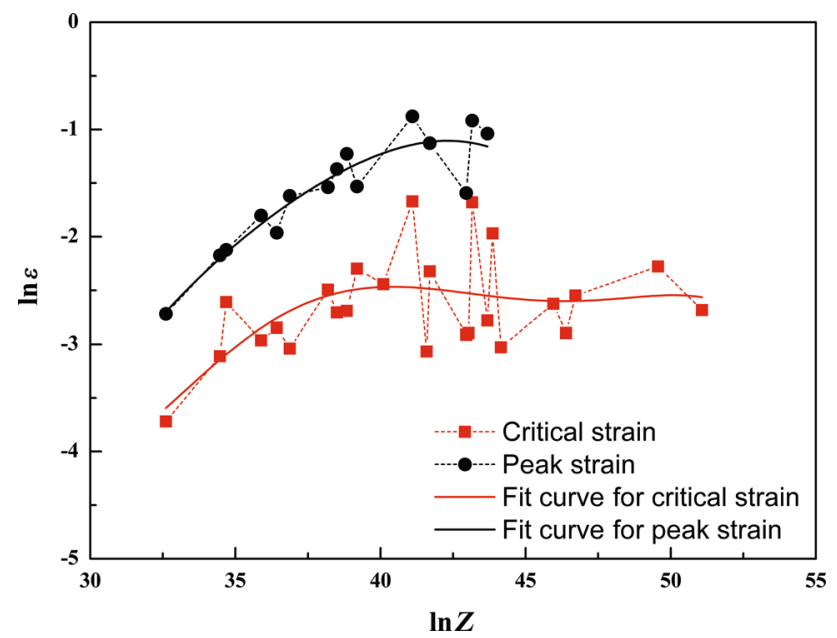

Fig. 9 Curves of $\ln \varepsilon_{\mathrm{c}}$ and $\ln \varepsilon_{\mathrm{p}}$ versus $\ln Z$

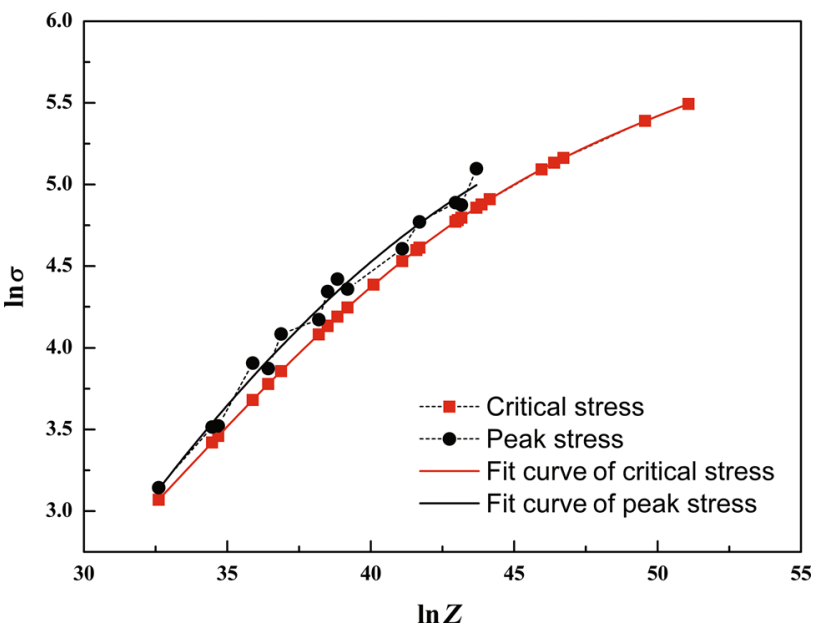

Fig. 10 Curves of $\ln \sigma_{\mathrm{c}}$ and $\ln \sigma_{\mathrm{p}}$ versus $\ln Z$

accumulation of a higher dislocation density promoting the initiation of DRX [29]. Besides, Stewart et al. gave another viewpoint to explain this tendency, which is contributed to the segregation of substitutional impurities $P$, in particular, to the sub-boundaries of newly nucleated DRX grains. Similar phenomenon has been reported in the nitridestrengthened steel [16] and 316 and 317 stainless steels [15].

Figure 10 shows the variation of peak stress and DRX initialization critical stress with the increase of $Z$, which has different results between the critical strain and peak strain. The value of $\ln \sigma_{c}$ displays a linearly increasing trend at first and then the growth rate slows down beyond 40. The decrease in growth rate might be attributed to the accumulation of a high dislocation density which can activate the initiation of DRX after the value of $\ln Z$ is beyond 40 . The critical strain for initiation of DRX will move forward to the high $\mathrm{Z}$ condition. Thus, the critical strain for DRX is sensitive to $Z$ value for the SIMP steel before the value of $\ln Z$ is lower than 40 , and the critical stress is sensitive to $Z$ value at all the time.

\subsection{Instability and Processing Maps of SIMP Steel}

The processing map can be applied to optimize the hot workability and control the microstructure in a wide temperature and strain rate regimes for hot working in terms of power dissipation ratio $\eta$, which is expressed as the following [30]:

$\eta=\frac{J}{J_{\max }}=\frac{2 m}{m+1}$,

where $J$ denotes the power dissipation by microstructure changes, $J_{\max }$ is the highest energy dissipated by dynamic microstructural changes, $m$ is the strain rate sensitivity. The 
variation of $\eta$ with temperature and strain rate constitutes a processing map, which exhibits various domains that may be correlated with specific microstructural mechanisms. In general, a higher $\eta$ means more energy to be consumed during the microstructure evolution and represents a better hot ductility of the steel. However, high value of $\eta$ may cause flow instability resulting in wedge cracking. Therefore, the criterion of flow instability condition has to be considered in order to elicit the unsafe region during hot deformation. The classic instability criterion was developed by Prasad [31], which was based on the irreversible thermodynamics of large plastic flow described by Ziegler [32]. The criterion $\xi(\dot{\varepsilon})$ is expressed by:

$\xi(\dot{\varepsilon})=\frac{\partial \ln [m /(m+1)]}{\partial \ln (\dot{\varepsilon})}+m$.

When $\xi(\dot{\varepsilon})$ becomes negative, microstructural instabilities, such as in the form of flow localization, will appear. The variation of strain rate sensitivity $m$ is calculated with temperature and strain rate, and then the variation of $\eta$ and $\xi(\dot{\varepsilon})$ can be constituted on a superimposed map including processing map and instability map, which delineates the region of power dissipation change and flow instability. Figure 11 shows a series of superimposed maps for the SIMP steel at the strain range of 0.1-0.9 with the contour lines of power dissipation (full line) and instability parameter (dotted line). The shadow region is described as the flow instability area where the parameter of $\xi(\dot{\varepsilon})$ is below 0 under the current hot working condition.

From Fig. 11, it is quite evident that high temperature and low strain rate are the optimum operating conditions as this region represents a highly efficient and stable region. Compared to early work by Zhang et al. [33], the SIMP steel has a relatively higher instability in the processing map than P92 steel under the same hot working condition, which is especially concentrated at the strain rate above $0.1 \mathrm{~s}^{-1}$ and the temperature below $1050{ }^{\circ} \mathrm{C}$. The flow instability is obviously sensitive to strain rate at all the hot working temperatures before the strain reaches up to 0.6, and the SIMP steel barely has good workability in the strain range of $0.3-0.4$ when the strain rate is higher than $1 \mathrm{~s}^{-1}$. The flow instability will be transformed to be temperature sensitive at the strain above 0.7 , which shows a none flow instability and higher power dissipation

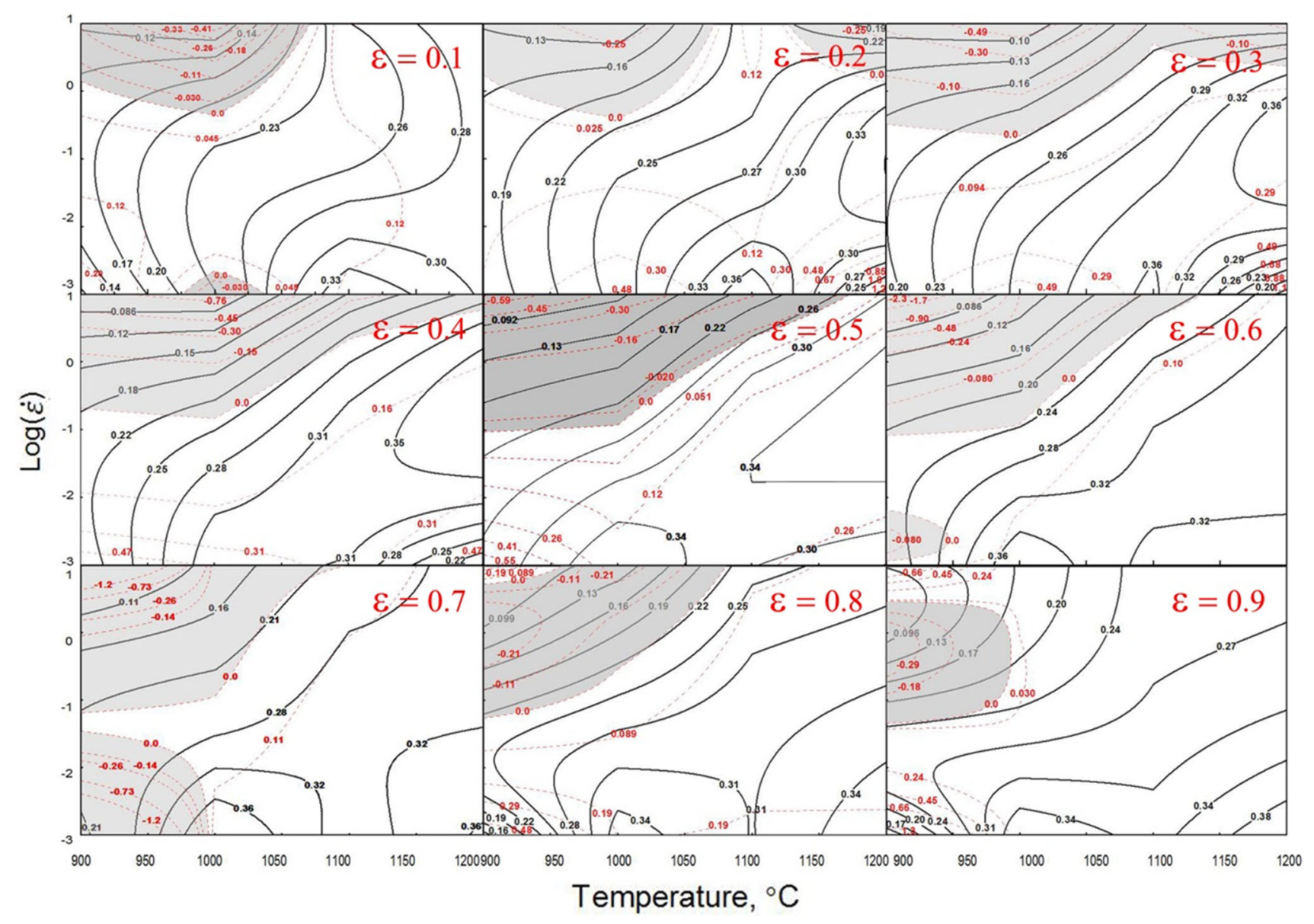

Fig. 11 Instability and processing maps in strain range of $0.1-0.9$ for SIMP steel 
efficiency region for providing a good workability after the temperature is above $1100{ }^{\circ} \mathrm{C}$ at all the experimental strain rates. Combining each kind of situation, the optimum hot processing condition for the SIMP steel can be determined as $1050-1200{ }^{\circ} \mathrm{C} / 0.001-0.1 \mathrm{~s}^{-1}$.

\section{Conclusions}

(1) DRX may occur even if there is no distinct peak on the flow curves. Inflections in strain hardening rate versus stress curves are stronger indications of occurrence of DRX.

(2) The critical strain had been determined precisely. The activity energies $Q_{\mathrm{DRV}}$ and $Q_{\mathrm{HW}}$ for the initiation of DRX and the peak strain were calculated to be $476.1 \mathrm{~kJ} / \mathrm{mol}$ and $462.7 \mathrm{~kJ} / \mathrm{mol}$, respectively.

(3) The constitutive equations for the SIMP steel at the deformation temperatures over a large range of 900-1200 ${ }^{\circ} \mathrm{C}$ were expressed and the critical stress $\sigma_{\mathrm{c}}$ and peak stress $\sigma_{\mathrm{p}}$ can be determined under the other deformation conditions using the equations.

(4) The obtained instability and processing maps suggest that the SIMP steel does not show workability as good as that of P92 Steel. The flow instability is obviously sensitive to strain rate at all the hot working temperatures before the strain reaches up to 0.6 , while it is sensitive to temperature when the strain is above 0.7 . The optimum processing condition for the SIMP steel is determined to be $1050-1200{ }^{\circ} \mathrm{C} / 0.001-0.1 \mathrm{~s}^{-1}$.

Acknowledgements This work was financially supported by the National Natural Science Foundation of China (No. 51874368) and the Project of CAS Key Laboratory of Nuclear Materials and Safety Assessment, Institute of Metal Research, Chinese Academy of Sciences (No. 2018NMSAKF03).

\section{References}

[1] Q.Q. Shi, J. Liu, W. Wang, W. Yan, Y.Y. Shan, K. Yang, Oxid. Met. 521, 83 (2015)
[2] E. Camus, N. Wanderka, S. Welzel, E. Materna-Morris, H. Wollenberger, Mater. Sci. Eng. A 250, 37 (1998)

[3] R.L. Klueh, J. Nucl. Mater. 378, 159 (2008)

[4] C. Liu, Q.Q. Shi, W. Yan, C.G. Shen, K. Yang, Y.Y. Shan, Y.Y. Shan, M.C. Zhao, J. Mater. Sci. Technol. (2019). https://doi.org/ 10.1016/j.jmst.2018.07.002

[5] Q.Q. Shi, J. Liu, H. Luan, Z.G. Yang, W. Wang, W. Yan, Y.Y. Shan, K. Yang, J. Nucl. Mater. 457, 135 (2015)

[6] J. Liu, Q.Q. Shi, H. Luan, W. Yan, W. Sha, W. Wang, Y.Y. Shan, K. Yang, Oxid. Met. 84, 1 (2015)

[7] O.I. Eliseeva, V.P. Tsisar, V.M. Fedirko, Y.S. Matychak, Mater. Sci. 40, 260 (2004)

[8] O.I. Eliseeva, V.P. Tsisar, Mater. Sci. 43, 230 (2007)

[9] M.C. Zhao, Y.Y. Shan, F.R. Xiao, K. Yang, Mater. Sci. Technol. 19, 355 (2003)

[10] H.Q. Huang, H.S. Di, N. Yan, J.C. Zhang, Y.G. Deng, R.D.K. Misra, J.P. Li, Acta Metall. Sin. (Engl. Lett.) 31, 503 (2018)

[11] M.C. Zhao, T. Hanamura, H. Qiu, K. Yang, Metall. Mater. Trans. A 37, 1657 (2006)

[12] J. Han, J.P. Sun, Y. Han, H. Liu, Acta Metall. Sin. (Engl. Lett.) 30, 1080 (2017)

[13] Y.C. Lin, X.M. Chen, Mater. Des. 32, 1733 (2011)

[14] Y.P. Li, R.B. Song, E.D. Wen, F.Q. Yang, Acta Metall. Sin. (Engl. Lett.) 29, 441 (2016)

[15] H.J. Mcqueen, S. Yue, N.D. Ryan, E. Fry, J. Mater. Process. Technol. 53, 293 (1995)

[16] W.F. Zhang, L. Xiao, W. Sha, W. Wang, W. Yan, Y.Y. Shan, K. Yang, Mater. Sci. Eng. A 590, 199 (2014)

[17] A.S. Taylor, P.D. Hodgson, Mater. Sci. Eng. A 528, 3310 (2011)

[18] H.J. Mcqueen, Met. Forum 4, 81 (1981)

[19] D.X. Wen, Y.C. Lin, X.H. Li, S.K. Singh, J. Alloys Compd. 764, 1008 (2018)

[20] H. Mirzadeh, A. Najafizadeh, ISIJ Int. 53, 680 (2013)

[21] N.D. Ryan, H.J. Mcqueen, J. Mater. Process. Technol. 21, 177 (1990)

[22] E.I. Poliak, J.J. Jonas, Acta Metall. 44, 127 (1996)

[23] C.M. Sellars, W.J. Mctegart, Memoires. Sci. Rev. Met. 63, 734 (1966)

[24] C.M. Sellars, W.J. Mctegart, Acta Metall. 14, 1136 (1966)

[25] F. Garofalo, Trans. AIME 227, 351 (1963)

[26] R. Shi, Z. Liu, J. Iron. Steel Res. Int. 18, 53 (2011)

[27] B. Wang, W. Fu, Z. Lv, P. Jiang, W. Zhang, Y. Tian, Mater. Sci. Eng. A 487, 108 (2008)

[28] M. Carsí, R. Allende, F. Peñalba, J.A. Jiménez, O.A. Ruano, Steel Res. Int. 75, 26 (2004)

[29] R. Sandström, R. Lagneborg, Scr. Metall. 9, 59 (1975)

[30] A. Momeni, K. Dehghani, Mater. Sci. Eng. A 528, 1448 (2011)

[31] Y.V.R.K. Prasad, Indian. J. Technol. 28, 435 (1990)

[32] H. Ziegler, Progress in Solid Mechanics (Wiley, New York, 1963)

[33] W. Zhang, W. Sha, W. Wang, W. Yan, Y. Shan, K. Yang, Mater. Sci. Eng. A 604, 207 (2014) 